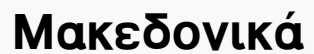

Tóp. 4, Ap. 1 (1960)

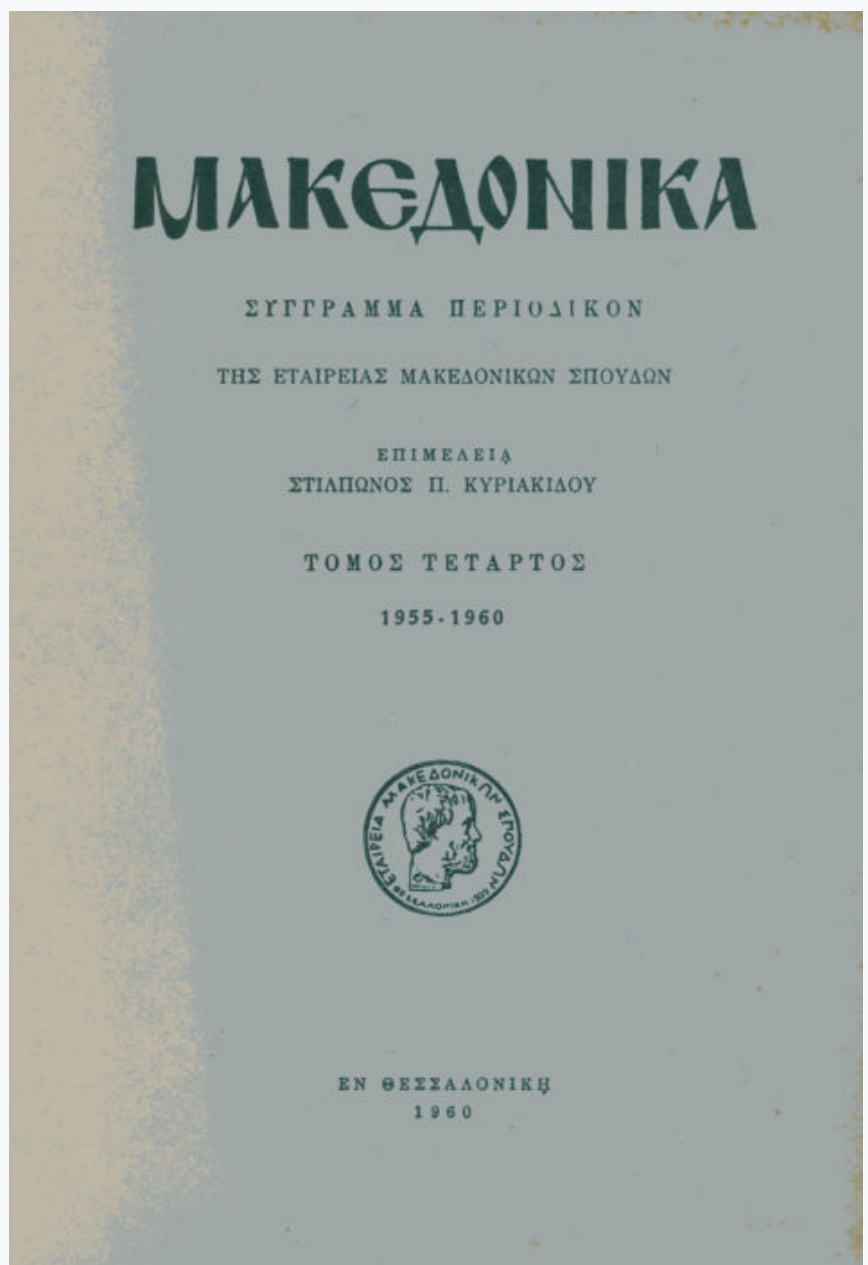

\section{Monica Krippner, Beyond Athens}

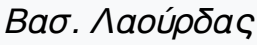

doi: $\underline{10.12681 / \text { makedonika.766 }}$

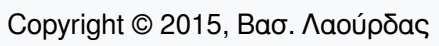

\section{(9) $(\Theta \odot$}

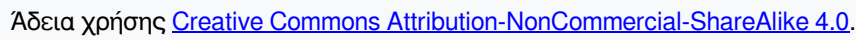

\section{Bıß入ıорачıкń avaчopá:}

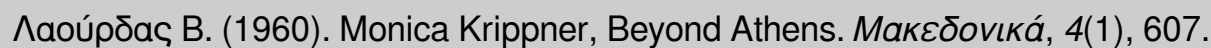
https://doi.org/10.12681/makedonika.766 


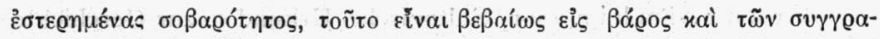

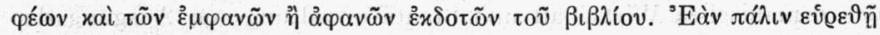

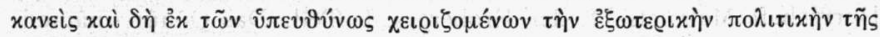

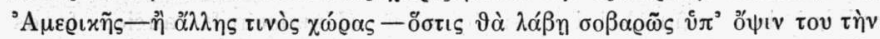

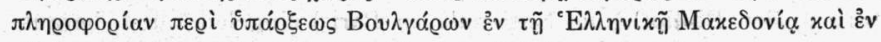

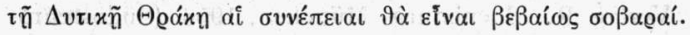

BAE. NAOYPAAE

M y r r ha L ot - B or odin e, Nicolas Cabasilas. Un maitre de la Spiritualité Byzantine au XIVe siècle. Éditions de Orante. $1958, \sigma \varepsilon \lambda .196$.

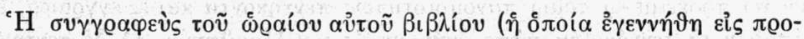

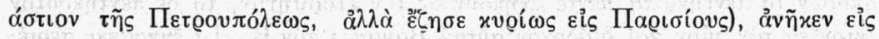

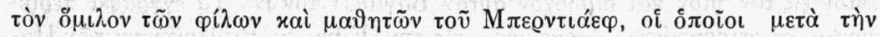

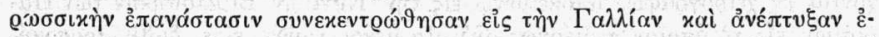

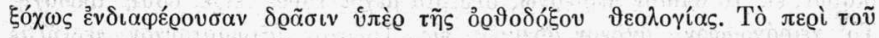

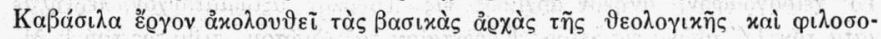


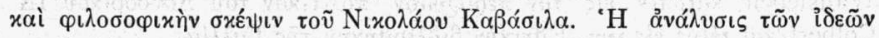

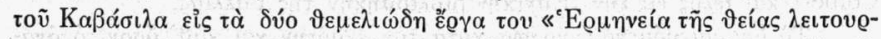

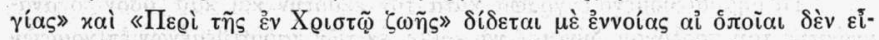

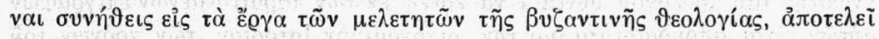

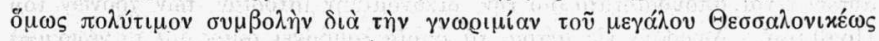

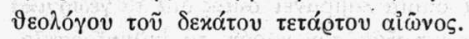

BAE. NAOYP $\triangle A \Sigma$

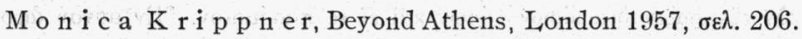

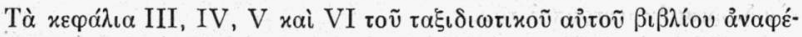

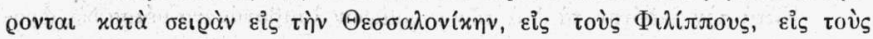

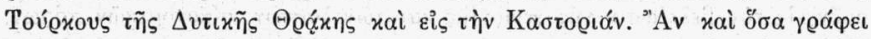

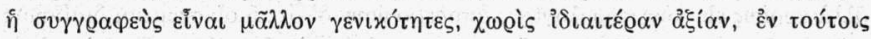

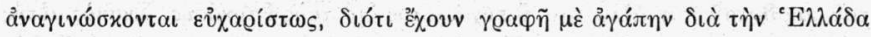

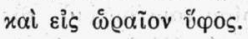

BAE. $\triangle A O Y P \triangle A \Sigma$

M o n ments of Thes s al oniki, Thessaloniki $\sigma \varepsilon \lambda .56$.

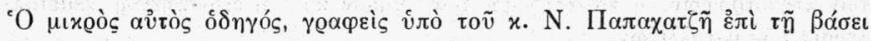

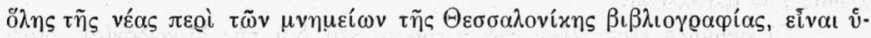
$\pi$

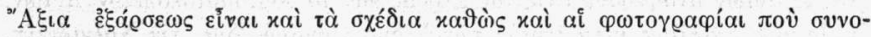

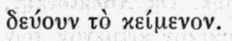

BAE. NAOYPAAE 